\title{
Comparative estimation of water saturation in carbonate reservoir: A case study of northern Iraq
}

\author{
Ghassan H. Ali ${ }^{1}$, Yahya J. Tawfeeq ${ }^{2}$, Mohammed Y. Najmuldeen ${ }^{3}$ \\ ${ }^{1,2,3}$ Petroleum Engineering Department, College of Engineering, University of Kirkuk, Kirkuk, Iraq
}

\begin{abstract}
Water saturation is among important petrophysical properties of rock used to assess the initial hydrocarbon in an exploration well. This paper studies five formations from the main limestone carbonate reservoir belong to an exploration field located in the northern part of Iraq. Additionally, we review water saturation models to choose the best one to this exploration field. There are several techniques of water saturation determination applied to estimate reservoir quality. Archie equation is considered one of these techniques; however, applying this model in shale formation gives errors in water saturation estimation. Three different models of water saturation, Simandoux, Indonesian, and Modified Simandoux, were chosen to estimate water saturation in shale beds. Our results demonstrated that the water saturation obtained from the Archie equation is higher than all other models. Furthermore, the Indonesian water saturation model is higher than Simandoux and Modified Simandoux water saturation models. The outcome of the Simandoux and Modified Simandoux were lower than those of Archie and Indonesian models. The accuracy of the water saturation model is evaluated by tends to be close to that of Archie water saturation model is considered negative. The reason is there are no production test results or saturation data from core analysis. The lowest average of water saturation is found in Simandoux and Modified Simandoux models. Depending on water saturation value, the good positive model is modified Simandoux or Simandoux model due to its lowest average value of water saturation. Besides, it can be used for further reservoir studies.
\end{abstract}

\begin{tabular}{ll}
\hline Keywords: & $\begin{array}{l}\text { Water saturation, Shale formations, Archie equation, Simandoux model, Indonesian } \\
\text { model }\end{array}$ \\
\hline
\end{tabular}

\section{Corresponding Author:}

Yahya J. Tawfeeq

Departement of Petroleum Engineering,

Collage of Engineering,

Kirkuk University, Iraq

Email: yahyapetroleum@yahoo.com

\section{Introduction}

In a reservoir pore space, water saturation is considered as the percentage of water. Determining the saturation of water is the most significant factor in reservoir evaluation by which original oil is measured according to the saturation of water, reservoir volume and porosity [1]. Water saturation could be estimated by using many methods, including Archie equation and capillary pressure data, and determined directly from the analysis of core samples. Methods based on petrophysical models represent the most common way of estimating water saturation. Depending on the amount of clay in the reservoir, water saturation is measured from distinct saturation models in petrophysical formation evaluation. All water saturation models established for water saturation estimation in shale formations are essentially an extension of the original Archie equation in clean formation with an additional parameter to accommodate shale amount and the electrical characteristics related to it. Currently, there are several models describing water saturation in shale beds because no unique acceptable results have been achieved. Finally, in the next section, we explain the models that are used to assess the hydrocarbon reservoirs based on the shale content and reservoir characteristics. 


\section{Literature Review}

The interpretation of electrical log for estimating the saturated hydrocarbon pores depends on the Archie equation. The equation is used to calculate the water saturation consisting of many parameters like the formation resistivity $(R t)$, porosity and formation of water resistivity. In 1942, two empirical relationships were derived by Archie, namely, resistivity index and formation factor. His first equation introduced by two parameters: the resistivity index $(R I)$ and water saturation $(S w)$ as follows [2]:

$$
R I=\frac{R t}{R o}=S w^{-n}
$$

where $(R t)$ refers to true rock resistivity partially saturated with the fluids, $(R o)$ is rock resistivity fully saturated with water (i.e., 100\% saturation) and $(n)$ is the exponent of saturation. Archie's second equation gives the correlation between porosity $(\varphi)$ and formation factor $(F)$, and it is represented by equation 2 :

$$
F=\frac{R o}{R w}=\frac{a}{\varphi^{m}}
$$

where $(R w)$ is the water (brine) resistivity, $(m)$ is the cementation factor, $(a)$ is a tortuosity factor. The difference between $R o$ and $R w$ is due to the presence of the matrix. Combining of (1) and (2) gives Archie's water saturation equation:

$$
S w=\left(\frac{a R w}{R t \varphi^{m}}\right)^{\frac{1}{n}}
$$

where $(S w)$ is water saturation of the uninvaded zone, $(a)$ is tortuosity factor, $(R w)$ is the resistivity of formation water at formation temperature, $(n)$ is the exponent of saturation, $(R t)$ is true formation resistivity from deep induction or deep laterolog corrected for invasion, $(\varphi)$ is formation porosity and $(m)$ is exponent of cementation. The Archie formula was established specifically for a clean formation. However, it does not reflect the clay materials. Archie equation is less appropriate for shale formation; therefore, other adapted models (shale formation saturation models) should be implemented to predict the reservoir hydrocarbon saturation. These models give the original Archie's equation further parameters, such as conductivity of shale. Generally, the following equation is used to calculate the conductivity of shale saturation models.

$$
C t=\frac{C w}{F}+C_{s h}
$$

where $C t$ is total conductivity of formation, $C w$ is water formation conductivity, $C_{s h}$ is shale conductivity and $F$ is formation factor. Leveaux and Poupon (1971) introduced the Indonesian Model for interpretation of clay formation. This model is used in the shale formations to measure effective water saturation. Furthermore, it is independent of the reservoir shale distribution. The following equation provides the relationship between the formation resistivity and the other parameters that affect it (including $V s h, S w R s h, R w$ and $R s h$ ):

$$
\frac{1}{R t}=\frac{V_{s h}^{c} S w}{R s h}+\frac{\varphi^{m} S_{w}^{n}}{a R w}
$$

where $(R t)$ refers to true resistivity of formation from deep resistivity $\log ,(V s h)$ is volume fraction of shale in formation, exponent $(c)$ is generally assumed to be 1 , and sometimes can be used greater values up to $2,(m)$ and $(n)$ are exponents of cementation and saturation, respectively and $(R s h)$ is shale resistivity

It is worth mentioning that equation 5 uses to overestimate water saturation in case the $(R s h / R w)$ ratio is small, and the proportion of shale is greater in the formation. Consequently, the following equation assumes more precise outcomes for efficient water saturation $\left(S_{w e}\right)$. 


$$
\frac{1}{\sqrt{R t}}=\left(\frac{V_{s h}^{\left(1-\frac{V s h}{2}\right)}}{\sqrt{R s h}}+\frac{\varphi^{\frac{m}{2}}}{\sqrt{a R w}}\right) S_{w e}^{\frac{n}{2}}
$$

Both Equations 5 and 6 depend on an accurate assessment of formation parameters to provide more acceptable outcomes in water saturation. Indeed, the Indonesian equation has been created to be employed in Indonesia since there are a relatively fresh-water formation and elevated shale content (which are deficiencies of other equations and have subsequently been discovered to be relevant in other fields) [4]. The Simandoux Model is developed using experiment testing. Many studies have been carried out on artificial mixtures of homogeneous formation and clay using Simandoux. They have recommended that the following resistivity can be stated by the following relation [5]:

$$
\frac{1}{R t}=\frac{V s h}{R s h}+\frac{\varphi^{m} S_{w}^{n}}{a R w}
$$

Modified Simandoux Equation is produced from Eq. (7) to give:

$$
\frac{1}{R t}=\frac{V s h S w}{R s h}+\frac{\varphi^{m} S_{w}^{n}}{a R w(1-V s h)}
$$

where $(R s h)$ refers to the resistivity of dispersed clay.

\section{Methodology and Results}

As mentioned earlier, this work studies five formations from the main limestone carbonate reservoir, namely, Fat'ha, Jeribe, Bajwan Dense, Bajwan Porous and Baba formations. These formations belong to Tertiary period carbonate reservoir sequences (Main Limestone) located in the northern region of Iraq. The contact of oil/water is fixed on the depth of $1500 \mathrm{~m}$ depending on the deep resistivity log reading and DST (drill stem test) report. Water saturation determination in clean or/and in shale formation involves several steps. These steps include the formation of water resistivity, $R w$ calculation, shale volume estimation, porosity estimation and additional parameters (will be described below).

\subsection{Clay volume determination}

The determination of reservoir petrophysical properties, such as porosity and reservoir fluids, are primarily based on shale volume estimation. Gamma-ray log utilizes the naturally emitted gamma radiation of the formation. The gamma rays emitted from the formation are calculated on the detectors of gamma rays. The gamma-ray reading can be expressed as a linear clay content function if there are no radioactive, non-clay minerals and the radioactive clay level is constant, the gamma-ray reading can be expressed as a linear clay content function. The gamma-ray index can be calculated as follows [8][10]:

$$
G R I=\frac{G R_{\log }-G R_{\min }}{G R_{\max }-G R_{\min }}
$$

where $(G R I)$ is gamma-ray index, percent, $\left(G R_{l o g}\right)$ is gamma-ray log reading of formation (API), $\left(G R_{\min }\right)$ is gamma-ray matrix or clay free zone (API) and $\left(G R_{\max }\right)$ is gamma-ray shale (i.e., $100 \%$ clay zone (API)). Equation 9 overestimates the volume of clay at non-shale intervals (i.e., clean formation) wealthy in other than shale radioactive minerals, particularly true for the radioactive formation and dolomite [6]. Because of clay volume overestimating using this method for the existence of radioactive minerals, which are non-clay 
minerals, some early scientists developed a non-linear model to estimate clay volume, such as Larionov (1969) for Tertiary Rocks.

$$
V s h=0.083\left(2^{3.7 * G R I}-1\right)
$$

where $(V s h)$ is shale volume. The results of calculated clay volume models are listed in Table 1 and plotted as frequency histogram in Figure 1. It can be seen that the clay volume is varied from formation to another. Hence, the maximum clay volume is observed in Jerebi formation, and the minimum one is observed in Bajwan Dense formation. A comparison between clay volume models indicates that the quantity of clay calculated from the conventional linear GR technique is comparatively greater than the nonlinear technique (Larionov for Tertiary rocks). Due to the existence of non-clay radioactive minerals like micas and feldspars, overestimation of clay quantity by the linear technique can result. This technique also assumes a linear relationship between the quantity of shale and the reading of gamma rays. The nonlinear model based on the particular geographic region and rock age corrects the quantity of shale from linear GR technique.

Table 1: Average shale volume values (as fraction).

\begin{tabular}{|c|c|c|c|c|c|c|c|}
\hline MODEL & Formation & Min & Max & Mean & P10 & P50 & P90 \\
\hline \multirow{5}{*}{ Non-Linear } & FAT'HA & 0.00098 & 0.9845 & 0.1385 & 0.0295 & 0.0759 & 0.3142 \\
\hline & JERIBE & 0.00426 & 0.9839 & 0.3217 & 0.0548 & 0.2641 & 0.6916 \\
\hline & $\begin{array}{l}\text { BAJWAN } \\
\text { DENSE }\end{array}$ & 0.00264 & 0.6927 & 0.0712 & 0.0114 & 0.0572 & 0.1102 \\
\hline & $\begin{array}{l}\text { BAJWAN } \\
\text { POROUS }\end{array}$ & 0.00698 & 0.8454 & 0.2507 & 0.0234 & 0.1844 & 0.6312 \\
\hline & BABA & 0.00486 & 0.8876 & 0.1973 & 0.0277 & 0.1001 & 0.4466 \\
\hline \multirow{5}{*}{ Linear } & FAT'HA & 0.00046 & 0.9944 & 0.3241 & 0.1182 & 0.2525 & 0.6092 \\
\hline & JERIBE & 0.01945 & 0.9941 & 0.5413 & 0.1972 & 0.5566 & 0.8693 \\
\hline & $\begin{array}{c}\text { BAJWAN } \\
\text { DENSE }\end{array}$ & 0.01217 & 0.8699 & 0.1981 & 0.0502 & 0.2038 & 0.3285 \\
\hline & $\begin{array}{l}\text { BAJWAN } \\
\text { POROUS }\end{array}$ & 0.03137 & 0.9399 & 0.4544 & 0.0967 & 0.4550 & 0.8377 \\
\hline & BABA & 0.02211 & 0.9573 & 0.3932 & 0.1303 & 0.3332 & 0.7949 \\
\hline
\end{tabular}

\subsection{Estimation of porosity}

Porosity is the porous space fraction that the rock matrix does not occupy. In the petroleum industry, different kinds of porosity are recognized. Only two kinds, namely, efficient and total porosities, are primarily regarded in use. Total porosity was determined according to Schlumberger's (1974) equation from the combination of Neutron - Density derived porosities that can be expressed as [9]:

$$
\varphi_{T}=\frac{\varphi_{N}+\varphi_{D}}{2}
$$

where $\varphi_{T}$ is Total porosity derived from Neutron-Density $\log , \varphi_{D}$ is porosity derived from Density $\log$ and $\varphi_{N}$ is porosity derived from Neutron log. 

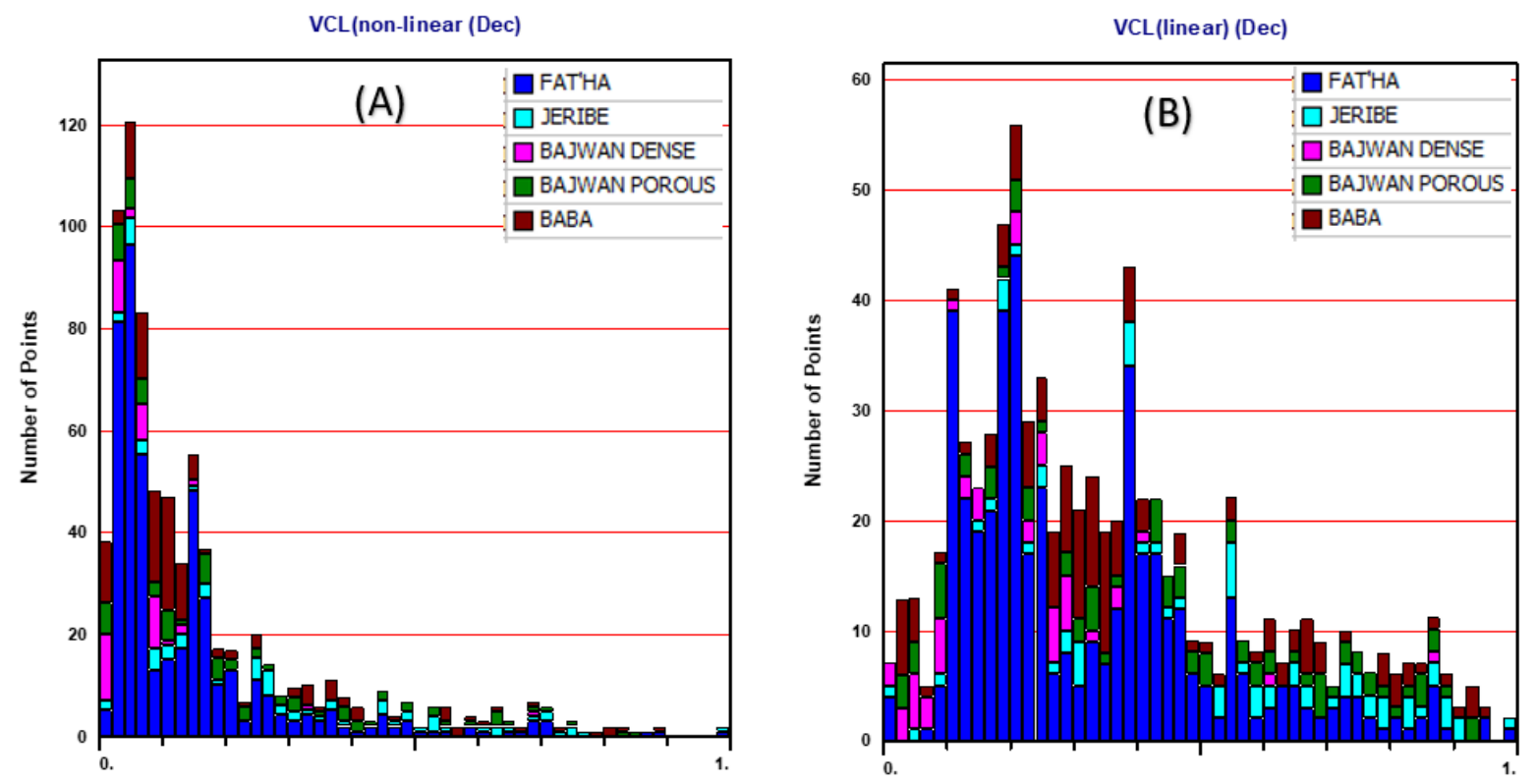

Figure 1. Clay volume histogram: (A) non-linear method (B) linear method.

Porosity from density log is derived depending on the bulk density and calculated using the equation of Wyllie et al. (1958), while the matrix density $\left(\rho_{\mathrm{ma}}\right)$ and the fluid density $(\rho \mathrm{f})$ are known:

$$
\varnothing \mathrm{D}=(\rho \mathrm{ma}-\rho \mathrm{b}) /(\rho \mathrm{ma}-\rho f)
$$

where $\rho_{\text {ma }}$ refers to matrix density $\left(2.87 \mathrm{gm} / \mathrm{cm}^{3}\right.$ for dolomite, $2.71 \mathrm{gm} / \mathrm{cm}^{3}$ for limestone and $2.61 \mathrm{gm} / \mathrm{cm}^{3}$ for sandstone) and $\rho \mathrm{f}$ is density of fluid $\left(1.1 \mathrm{gm} / \mathrm{cm}^{3}\right.$ for saline water and $1 \mathrm{gm} / \mathrm{cm}^{3}$ for freshwater,).

By using Schlumberger's (1998) equation, the effective porosity $\left(\varphi_{e}\right)$ can be calculated as follows [3][13]:

$$
\varphi_{\mathrm{e}}=\varphi_{\mathrm{t}} *\left(1-\mathrm{V}_{\text {clay }}\right)
$$

The results of the mathematical averaging calculated effective porosity are listed in Table (2) and plotted as frequency histogram in Figure 2. Based on the results of mathematical porosity averaging, the porosity is varied from formation to another. The maximum effective porosity is observed in BABA formations, and minimum effective porosity is observed in BAJWAN and JERIBE formations.

Table 2. Average effective porosity values (as fraction).

\begin{tabular}{|c|c|c|c|c|c|c|}
\hline Formation & Min & Max & Mean & P10 & P50 & P90 \\
& & & & & & \\
\hline FAT'HA & 0.0001 & 0.23895 & 0.089475 & 0.0001 & 0.089075 & 0.17808 \\
\hline JERIBE & 0.0001 & 0.23904 & 0.017263 & 0.0001 & 0.0001 & 0.044199 \\
\hline BAJWAN DENSE & 0.0001 & 0.12002 & 0.04223 & 0.008893 & 0.033644 & 0.099903 \\
\hline $\begin{array}{c}\text { BAJWAN } \\
\text { POROUS }\end{array}$ & 0.0001 & 0.1569 & 0.046529 & 0.0001 & 0.050141 & 0.085767 \\
\hline BABA & 0.0001 & 0.27081 & 0.11873 & 0.010598 & 0.13658 & 0.17979 \\
\hline Overall Porosity & 0.0001 & 0.27081 & 0.080702 & 0.0001 & 0.072352 & 0.17397 \\
\hline
\end{tabular}




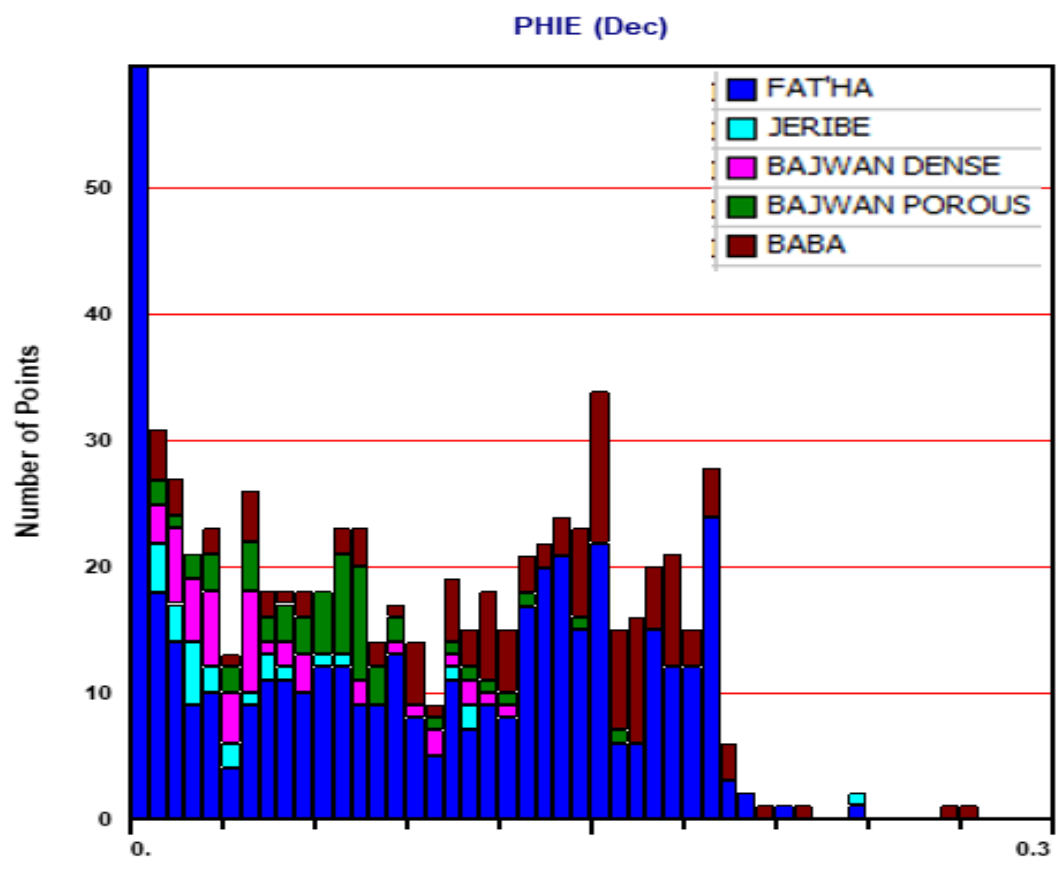

Figure 2. Effective porosity histogram for all formations under study

\subsection{Formation of Water Resistivity $(\mathrm{Rw})$ and True Resistivity Determination}

True formation resistivity values $(R t)$ are provided straight from the uninvaded zone's deep Laterolog (LLD). Similarly, shale resistivity $(R s h)$ was acquired for each formation from the same resistivity (i.e., deep resistivity) $\log$ in the shale zone intervals and its values were determined as follows: 'Fat'ha' Fm. $=1.92 \Omega \mathrm{m}$, 'Jeribe' Fm. $=4.47 \Omega$ m, 'Bajwan Dense' Fm. $=5.19 \Omega$ m, 'Bajwan Porous' Fm. $=10.1 \Omega$ m and 'Baba' Fm. $=7.84$ $\Omega \mathrm{m}$. Formation of water resistivity was determined using equation (14) depending on the salinity of water formation ( $\mathrm{NaCl}$ concentration) at the laboratory temperature [7][12]:

$$
R w @ 75=0.0123+\frac{3647.5}{[\operatorname{NaCl}(p p m)]^{0.955}}
$$

Formation of water resistivity $(R w)$ was measured in this study using equation 14 above by taking the value of $\mathrm{NaCl}$ from DST test equal to $70000 \mathrm{ppm}$ at $118^{\circ} \mathrm{F}$. The value of $R w$ was found to be equal to $(0.065 \Omega \mathrm{m})$ and used with all water saturation models calculations (clay and non-clay models).

\subsection{Tortuosity, Saturation Exponent and Cementation Factor Determination}

Archie exponents ( $\mathrm{a}, \mathrm{m}$ and $\mathrm{n}$ ) were used in original Archie work who proposed $\mathrm{a}=1.0$ and $\mathrm{m}=1.8$ to 2.0 for his data set. Depending on the experimental data, Archie suggested that $n=2.0$, and this value is still widely used in absence of experimental data[14]. Following work by Exxon investigators for several sandstone rocks recommended to use the Humble formula with $(a=0.61)$ and $(m=2.15)$ [15]. Carbonates also have been studied and yielded a recommendation to use the Shell formula. However, carbonate pore and fracture networks vary greatly, and $\mathrm{m}$ values from 1.0 to 3.0 may be required[16]. Clearly, $\mathrm{m}$ is not a constant, but varies with rock type. In this study, it is assumed that the values of the exponent of saturation $(n)$ and cementation factor $(m)$ as ' 2 '; while the tortuosity $(a)$ is equal to ' 1 '. 


\section{Water saturation calculation}

Uninvaded zone water saturations were calculated using both clean equation and shale formation saturation equations as followed below. The water saturation is determined by Archie's equation for clean formation using [11]:

$$
S_{w}=\left(\frac{a R_{w}}{R_{t} \varphi^{m}}\right)^{\frac{1}{n}} \quad \text { or } \quad S_{w}=\sqrt{\frac{0.065}{R_{t} \varphi^{2}}}
$$

Additionally, the shale formation of water saturation can be calculated using the following equations:

(i)

\section{Indonesian Equation}

$$
\frac{1}{\sqrt{R t}}=\left(\frac{V_{s h}^{\left(1-\frac{V s h}{2}\right)}}{\sqrt{R s h}}+\frac{\varphi^{\frac{m}{2}}}{\sqrt{a R w}}\right) S_{w e}^{\frac{n}{2}} \quad \text { or } \quad \frac{1}{\sqrt{R t}}=\left(\frac{V_{s h}^{\left(1-\frac{V s h}{2}\right)}}{\sqrt{R s h}}+\frac{\varphi}{\sqrt{0.065}}\right) S w e
$$

(ii)

\section{Simandoux Equation}

$$
\frac{1}{R t}=\frac{V s h}{R s h}+\frac{\varphi^{m}}{a R w} S_{w}^{n} \quad \text { or } \quad \frac{1}{R t}=\frac{V s h}{R s h}+\frac{\varphi^{2}}{0.065} S_{w}^{2}
$$

(iii) Modified Simandoux Equation

$$
\frac{1}{R t}=\frac{V s h S w}{R s h}+\frac{\varphi^{m} S_{w}^{n}}{a R w(1-V s h)} \quad \text { or } \quad \frac{1}{R t}=\frac{V s h S w}{R s h}+\frac{\varphi^{2} S_{w}^{2}}{0.065(1-V s h)}
$$

where $(a)$ is tortuosity (assume $a=1),(m)$ is cementation factor (assume $m=2),(n)$ is saturation exponent (assume $n=2),(R w)$ is formation of water resistivity $(R w=0.065 \Omega \mathrm{m}),(R s h)$ is shale resistivity, $(R t)$ is formation resistivity, $(S w)$ is water saturation and $\varphi$ is formation porosity. The results of calculated water saturation models are listed in Table 3 and plotted as frequency histogram in Figure 3. The research findings showed that the overall Archie model's average water saturation values $(63.6 \%)$ were greater than shale models. The Indonesian model produces an average $(40.185 \%)$ water saturation value that is greater than that of Simandoux and Modified Simandoux model. The results showed that Simandoux and Modified Simandoux models obtained the smallest average of water saturation (33.43\%), which was lower than that of Archie and Indonesia models. Therefore, Simandoux and Modified Simandoux models are more suitable for future studies due to their lowest average of water saturation value.

\section{Results discussion}

There are wide arguments and discussions about the best accurate estimation among P50, P90, P10 and mathematical mean (average). Many researchers assert that the 'mathematical mean' estimation is better than other statistical estimation methods [19]. This argument suggests that the mean will include both higher and lower observations which will facilitate the differences when summed together. Also, some researchers argue that both percentiles (P10 and P90) give confusing results; while 10\% percentile (P10) gives underestimates of water saturation and 90\% percentile (P90) gives overestimate of saturation [19]. Figure 4 shows the differences results of (P10) and (P90) for five formations estimated by Modified Simandoux Model. However, 
the focus of this study is on 50\% percentile (P50) and "mathematical mean", which is a hard one. There is a misunderstanding about 50\% percentile (P50) that it is the same as mathematical mean estimates. Specifically, if the probability distribution function is symmetrical for the points, the mean is an alternative expression of $50 \%$ percentile (P50) in this case only [19]. For distributions wherever the points resort to be tilted, the 50\% percentile (P50) and the mathematical means start to deviate. So, one can ask which is the finest? The argument used for mathematical mean provides the appropriate outcomes if the distribution is symmetrical, but then again, if the distribution is asymmetrical, it might be better to reconsider and perhaps look at the 50\% percentile (P50).
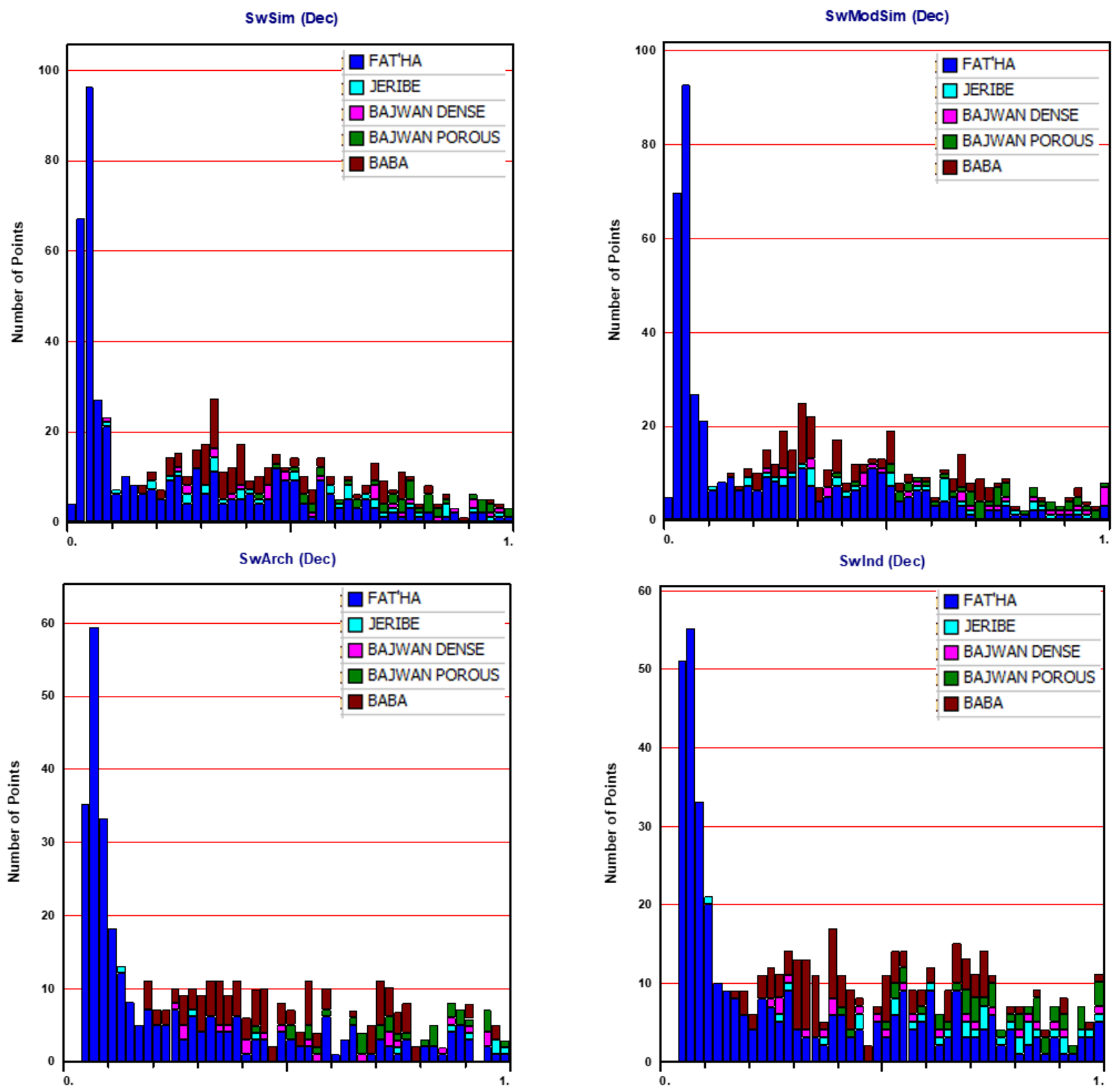

Figure 3. Clay water saturation models histogram determined using different models for all formations under study. 
Table 3. Overall water saturation statistics results for each formation.

\begin{tabular}{|c|c|c|c|c|c|c|c|}
\hline Formation (m) & Sw Model & Min & Max & Mean & $\mathrm{P} 10$ & P50 & P90 \\
\hline \multirow{4}{*}{$\begin{array}{c}\text { FAT'HA } \\
(1303-1416)\end{array}$} & Archie & 0.04580 & 0.9882 & 0.2574 & 0.0584 & 0.1204 & 0.7136 \\
\hline & Indonesian & 0.04356 & 0.9853 & 0.2990 & 0.0564 & 0.1616 & 0.7359 \\
\hline & Simandoux & 0.01631 & 0.9834 & 0.2290 & 0.0343 & 0.0969 & 0.5816 \\
\hline & $\begin{array}{c}\text { Modified } \\
\text { Simandoux }\end{array}$ & 0.01612 & 0.9999 & 0.2271 & 0.0338 & 0.0945 & 0.5704 \\
\hline \multirow{4}{*}{$\begin{array}{c}\text { JERIBE } \\
(1416-1433)\end{array}$} & Archie & 0.12587 & 0.9891 & 0.7006 & 0.2837 & 0.8663 & 0.9747 \\
\hline & Indonesian & 0.11947 & 0.9825 & 0.6805 & 0.3652 & 0.7331 & 0.9187 \\
\hline & Simandoux & 0.08007 & 0.9798 & 0.5207 & 0.2353 & 0.5191 & 0.8527 \\
\hline & $\begin{array}{c}\text { Modified } \\
\text { Simandoux }\end{array}$ & 0.1096 & 0.9462 & 0.5156 & 0.2447 & 0.5103 & 0.8382 \\
\hline \multirow{4}{*}{$\begin{array}{c}\text { BAJWAN } \\
\text { DENSE } \\
(1433-1446)\end{array}$} & Archie & 0.24132 & 0.9428 & 0.5900 & 0.2797 & 0.5757 & 0.9144 \\
\hline & Indonesian & 0.24072 & 0.999 & 0.5732 & 0.2793 & 0.5485 & 0.8931 \\
\hline & Simandoux & 0.08007 & 0.9760 & 0.5754 & 0.2793 & 0.5568 & 0.9039 \\
\hline & $\begin{array}{c}\text { Modified } \\
\text { Simandoux }\end{array}$ & 0.23984 & 0.9999 & 0.6417 & 0.3256 & 0.6744 & 0.9907 \\
\hline \multirow{4}{*}{$\begin{array}{c}\text { BAJWAN } \\
\text { POROUS } \\
(1446-1466)\end{array}$} & Archie & 0.4351 & 0.9909 & 0.7435 & 0.5452 & 0.7249 & 0.9522 \\
\hline & Indonesian & 0.40882 & 0.9998 & 0.7568 & 0.5371 & 0.7510 & 0.9436 \\
\hline & Simandoux & 0.42165 & 0.9997 & 0.7385 & 0.5392 & 0.7535 & 0.9371 \\
\hline & $\begin{array}{c}\text { Modified } \\
\text { Simandoux }\end{array}$ & 0.39685 & 0.9987 & 0.7310 & 0.5329 & 0.7408 & 0.9303 \\
\hline \multirow{4}{*}{$\begin{array}{c}\text { BABA } \\
(1466-\text { OWC })\end{array}$} & Archie & 0.18168 & 0.9713 & 0.4897 & 0.2604 & 0.4522 & 0.7584 \\
\hline & Indonesian & 0.17129 & 0.9961 & 0.4757 & 0.255 & 0.4165 & 0.7278 \\
\hline & Simandoux & 0.16669 & 0.9783 & 0.4648 & 0.2543 & 0.3958 & 0.7525 \\
\hline & $\begin{array}{c}\text { Modified } \\
\text { Simandoux }\end{array}$ & 0.15932 & 0.97665 & 0.4507 & 0.244 & 0.3834 & 0.71803 \\
\hline \multirow{4}{*}{$\begin{array}{l}\text { All Interval } \\
\text { Depth } \\
1303 \text {-OWC }\end{array}$} & Archie & 0.046 & 0.99988 & 0.636 & 0.075745 & 0.75848 & 0.99998 \\
\hline & Indonesian & 0.043568 & 0.99982 & 0.40185 & 0.062196 & 0.35166 & 0.83213 \\
\hline & Simandoux & 0.016319 & 0.99975 & 0.33425 & 0.037749 & 0.30067 & 0.75259 \\
\hline & $\begin{array}{c}\text { Modified } \\
\text { Simandoux }\end{array}$ & 0.016122 & 0.99998 & 0.33429 & 0.037297 & 0.29664 & 0.74087 \\
\hline
\end{tabular}



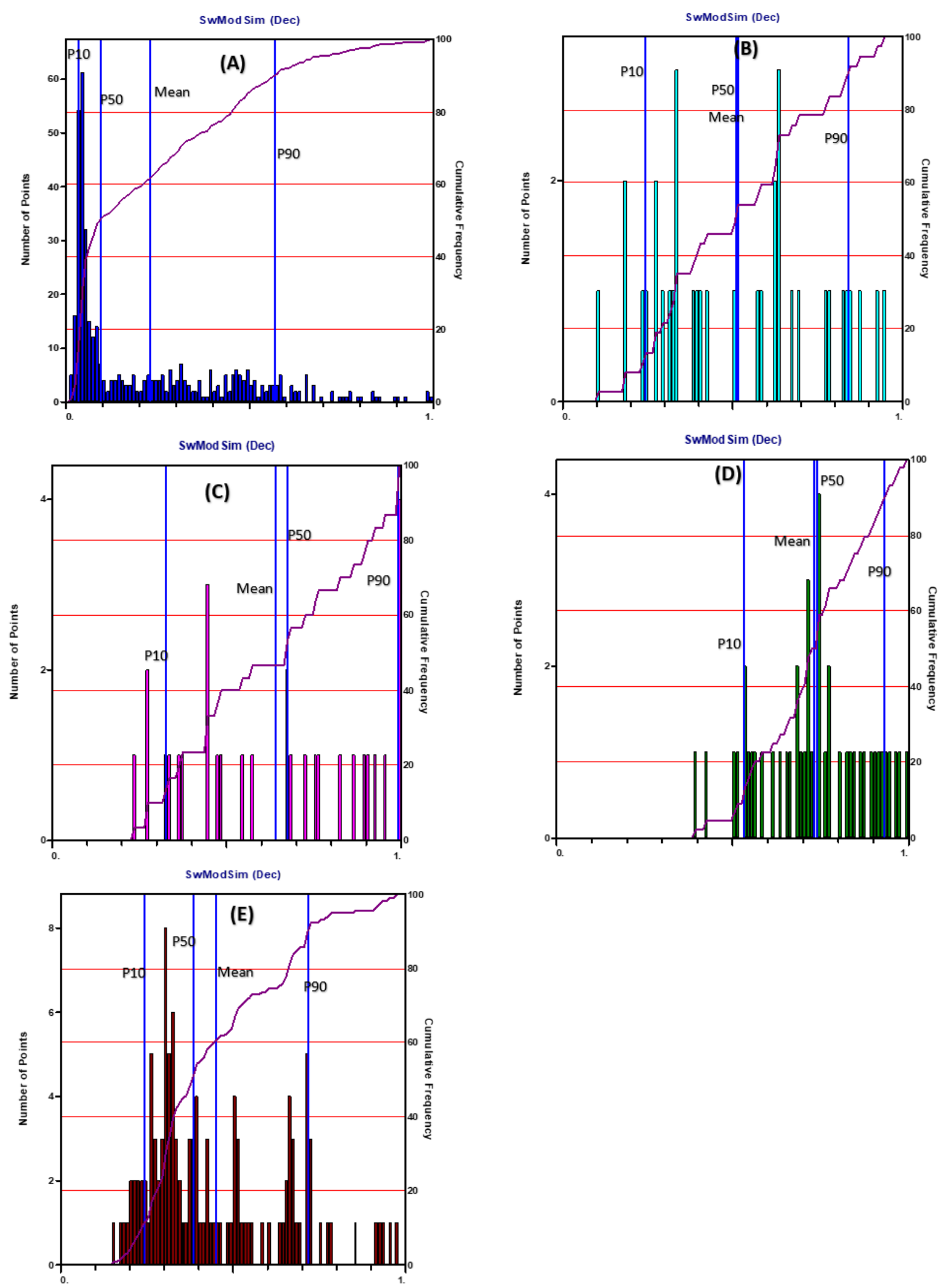

Figure 4. Arithmetic average vs. percentile statics water saturation resulted from modified Simandoux Model for: (A) FAT'HA; (B) JERIBE; (C) BAJWAN DENSE; (D) BAJWAN POROU; (E) BABA Formations. 
The results from percentile statistics have shown that the water saturation value from the Archie equation at P50 was $75.85 \%$, which was higher than that of all other models. The Indonesian model produces water saturation about P50 $=35.16 \%$, which was higher than that of Simandoux and Modified Simandoux models. The outcomes of the Simandoux and Modified Simandoux at P50 were 30.067\% and 29.66\%, respectively, which were lower than those of Archie and Indonesian models. Table 3 shows that the water saturation amount is very high in some formations. Through calculation process, some values of water saturation approach the value of 1, are found. The maximum value for water saturation fraction can be (1), which shows the $100 \%$ saturation. However, these exceeding saturation values led the average saturation to increase up to such numbers as 0.95221 and 0.99075 , for example. This error is probably because the saturation exponent and cementation factor are conventionally assumed to be ' 2 ' for the saturation estimation. The exponent of saturation and cementation factor are functions of many parameters. Some of the affecting parameters are pore size and its distribution. Therefore, it would be wrong to assume that the saturation exponent and cementation factor are just simply equal to '2'. These parameters must be determined for proper and reasonable water saturation before calculating it. The Indonesian model's average of water saturation is comparatively greater than the other two shale models, but it is lower than that of Archie model. Compared to the other two models of shale formation, Simandoux and the modified Simandoux models produced the lowest mean of water saturation $\left(S w_{\text {avg }}\right)$. The results from of this study have shown that; the average water saturation value from Archie equation is about $63.6 \%$ were higher than all other models. The Indonesian model produces mean value of water saturation about $40.18 \%$ which is higher than Simandoux and Modified Simandoux model. The outcome of the Simandoux and Modified Simandoux is about $33.42 \%$ which were lower than Archie model and model of Indonesian. Because there are no production test results or saturation data from core analysis; the result of any shaly-formation model that tends to be close or similar to the result of Archie will be considered pessimistic. Therefore, the good optimistic model depending on water saturation value was modified Simandoux or Simandoux model due to its lowermost average value of water saturation and it is can be used for the further reservoir studies.

\section{Conclusions}

In this study, the following conclusions drawn from the results of the study. Using Archie equation model in shale formation gives errors in water saturation estimation because of clay impacts on Archie equation parameters. There are many water saturations models have been established to account for shale effect. Inappropriately, there is no exceptional model that seems to appropriate all shale beds. Note that each of these saturation equations is affected differently by several factors, such as clay volume, porosity, saturation exponent and formation of water resistivity. In absence of core and production tests results, the result of any shale formation model that tends to be close or similar to that of Archie model will be considered negative. Therefore, Archie model will be used as a reference foundation for other models. The model of Archie expected greater water saturation $(S w)$ results relative to models of shale formation because of the impacts of shale or clay. Shale has a significant effect on most logging tools, such as porosity logs and resistivity logs. Because water saturation is a function of formation resistivity $(R t)$, porosity and formation of water resistivity $(R w)$, therefore overestimates of water saturation will result using Archie Equation. The modified Simandoux model implementation is comparable to Simandoux with a minor modification to Simandoux's original model by multiplying the factor $\left(1-V_{\text {shale }}\right)$ to the term " $a R w$ ". Again, it is important to remember that the parameters of Archie $(a, m$ and $n)$ must be determined earlier than water saturation determination for adequate and sensible water saturation estimations. Future research should consider the core and production test data to choose more accurate water saturation model for this exploration well.

\section{References}

[1] Fleury, M., Efnik, M. \& Kalam, M.Z. (2004). Evaluation Of Water Saturation From Resistivity In A Carbonate Field From Laboratory to Logs. International Symposium of the Society of Core Analysts. SCA2004-22. Abu Dhabi.

[2] Chantsalmaa, Dalkhaa. (2005). Study of Modeling of Water Saturation in Archie and Non-Archie Porous Media (master's thesis). Middle East Technical University,

[3] Murtadha, Zainab I. (2012). Reservoir Evaluation of Yamama Formation of Ratawi Oil Field (Unpublished master's thesis). Baghdad University, Petroleum Engineering Department, Iraq. 
[4] Worthington, P. F. (1985). The Evolution Of Shaly-Sand Concepts In Reservoir Evaluation. Society of Petrophysicists and Well-Log Analysts (SPWLA), 26(01), 1-18.

[5] Aldalawy, Ammar A. (2012). Variation of Petrophysical Properties in Abughirab And Fauqi Oil Fields/ Asmari Reservoir (Unpublished master's thesis). Baghdad University, Petroleum Engineering Department, Iraq.

[6] Kamel, M. H. \& Mabrouk W. M. (2003). Estimation Of Shale Volume Using A Combination Of The Three Porosity Logs. Journal of Petroleum Science and Engineering, 40(3-4), 145-157. https://doi.org/10.1016/S0920-4105(03)00120-7.

[7] Mian, M. A. (1992). Petroleum Engineering Handbook for Practicing Engineer. Pennwell Corp (January 1, 1992) .Tulsa, Oklahoma.

[8] Cruz,D. \& Faria, B. D. (2012). Interactive Petrophysics Basic User's Guide. Norwegian University of Science and Technology (NTNU). Retrieved https://www.scribd.com/document/286541698/Interactive-Petrophysics-Basic-User-s-Guide.

[9] Schlumberger (1974). Log Interpretation Manual/Applications. Houston, Schlumberger Well Service, Inc.V.2, 116p.

[10] Bassiouni Z. (1994). Theory Measurement and Interpretation of Well Logs. Society of Petroleum Engineers, SPE Textbook Series Vol. 4, ISBN: 978-1-55563-056-0.

[11] Asquith, G. \& Krygowski, D. (2004). Basic Well Log Analysis. The American Association of Petroleum Geologists, Tulsa, Oklahoma, Second Edition.

[12] Tiab, D. \& Erle C. Donaldson. (2011). Petrophysics: Theory and Practice of Measuring Reservoir Rock and Fluid Transport Properties. Gulf Professional Publishing, Third Edition. ISBN: 9780123838490.

[13] Ezeke, N. (2010). Petroleum Reservoir Engineering Practice. Prentice Hall, First Edition. ISBN-13: 9780133807424.

[14] Archie, G.E. (1942). The Electrical Resistivity Log as an Aid in Determining Some Reservoir Characteristics. Trans. of AIME, 146 (1), 54-62.

[15] Winsauer, W.O., Shearin H.M., Masson P.H., \& Williams M. (1952). Resistivity of Brine Saturated Sands in Relation to Pore Geometry. AAPG Bull, 36 (2), 253-277.

[16] Schlumberger (1991). Log Interpretation Principles/Applications. Schlumberger Educational Services, 3rd Printing, Houston, Texas.

[17] Zorin V. A., Baurova N.I., Pegachkov A. A. (2019). Assessment of products risks of mechanical engineering by results of diagnosing. Periodicals of Engineering and Natural Sciences. Vol. 7, No. 1, June 2019, pp.287-293

[18] Mabvuto MWANZA, Jamel CHACHAK, Numan S. ÇETIN, Koray ÜLGEN(2017). Assessment of Solar Energy Source Distribution and Potential in Zambia. Periodicals of Engineering and Natural Sciences. Vol.5, No.2, June 2017, pp. 103 116

[19] Yaşar Selman Gültekin, Pınar Gültekin, Osman Uzun, Hande Gök (2017). Use of Structural Equation Modeling in Ecotourism: A Model Proposal. Periodicals of Engineering and Natural Sciences. Vol.5, No.2, June 2017, pp. 145 151 